\title{
Development of an Adverse Outcome Pathway for the Onset of Hypertension by Oxidative Stress-Mediated Perturbation of Endothelial Nitric Oxide Bioavailability
}

\author{
Frazer J. Lowe,, Karsta Luettich,' Marja Talikka, Vy Hoang,, Linsey E. Haswell, \\ Julia Hoeng, and Marianna D. Gaca ${ }^{1}$
}

\begin{abstract}
Hypertension is a cardiovascular risk factor that has a profound influence on cardiovascular morbidity and mortality. While good progress has been made in terms of identifying and managing this risk factor for patient care, methods to assess the potential of chemical compounds to induce hypertension or to assess the efficacy of consumer products (e.g., e-cigarettes) targeted at reducing disease burden remain largely limited to epidemiological associations and in vivo studies. The field of toxicology has undergone a paradigm shift toward the replacement of in vivo testing in toxicological risk assessment. The adverse outcome pathway (AOP) framework could facilitate improved knowledge-based risk/benefit assessment of chemicals or consumer products, respectively, without the necessity of animal testing. Furthermore, to facilitate a more timely, cost effective, and ethical solution for risk/efficacy assessment purposes, integrated testing strategies are required, which do not heavily rely on in vivo studies. In this study, we present the supporting information on an AOP describing how vascular endothelial peptide oxidation leads to hypertension through perturbation of endothelial nitric oxide bioavailability, leading to impaired vasodilation. We also discuss the essentiality of the key events (KEs), and biological plausibility and empirical support of KE relationships, in accordance with the Organisation for Economic Cooperation and Development (OECD) handbook. This AOP could be a useful tool to serve as a foundation for a future integrated testing strategy for the regulatory assessment of the harm reduction potential of e-cigarettes relative to conventional tobacco products and other consumer products, which aim to reduce cardiovascular disease risk.
\end{abstract}

Keywords: adverse outcome pathway, cardiovascular disease, eNOS, hypertension, nitric oxide

\section{Introduction}

$\mathbf{C}$

ARDIOVASCULAR DISEASES are the leading cause of morbidity and mortality in a global society. ${ }^{1-3}$ Despite increased awareness and preventative activities, various behavioral risk factors, including tobacco smoking, obesity, sedentary lifestyle, and poor nutritional status, continue to serve as causative stimuli for the development of cardiovascular diseases. ${ }^{3}$ The American Heart Association has identified hypertension as one of five health factors contributing to the development of cardiovascular diseases/events. Based on 2009-2012 data, 32.6\% of US adults $\geq 20$ years of age have hypertension, which represents $=80.0$ million US adults. ${ }^{3}$
Given the associated morbidity and costs to manage the condition through pharmacological interventions, recent efforts have focused on preventative initiatives to raise awareness of cardiovascular health among healthcare practitioners and the general population while various industries work upon therapeutic interventions and/or consumer products aimed at risk reduction.

Hypertension is a multifactorial disorder not only primarily associated with increasing age but also influenced by a number of other risk factors, including xenobiotic exposure. ${ }^{4}$ Endothelial dysfunction underlies the development of hypertension and is defined as the imbalance between the production and bioavailability of endothelium-derived relaxing

\footnotetext{
${ }^{1}$ British American Tobacco (Investments) Ltd., Group Research and Development, Southampton, United Kingdom.

${ }^{2}$ Philip Morris International R\&D, Philip Morris Products S.A. (part of Philip Morris International group of companies), Neuchatel, Switzerland.

${ }^{3}$ Selventa, One Alewife Center, Cambridge, Massachusetts.

(C) Frazer J. Lowe et al., 2017; Published by Mary Ann Liebert, Inc. This Open Access article is distributed under the terms of the Creative Commons License (http://creativecommons.org/licenses/by/4.0), which permits unrestricted use, distribution, and reproduction in any medium, provided the original work is properly cited.
} 
and contractile factors. Furthermore, endothelial dysfunction is associated with increased bioavailability of reactive oxidant species and decreased antioxidant capacity, also characterized as oxidative stress. ${ }^{5}$ By (i) eliminating or reducing the exposure to stimulators of endothelial oxidative stress or (ii) using a consumer product that offers reduced risk compared with a currently used product, it follows that one can reduce the overall risk of developing hypertension in a population.

From a toxicological point of view, the focus of risk factor reduction resides in (i) the understanding and control of exposure to xenobiotic compounds, which have the potential to cause and/or accelerate the onset of hypertension, and (ii) efficacy assessments of consumer products, which either ameliorate the effects of (e.g., health supplements) or reduce exposure to (e.g., e-cigarettes) harmful xenobiotics. To determine which compounds could be of toxicological concern for the development and progression of hypertension, an understanding of the biology of endothelial dysfunction and hypertension is required. Furthermore, given the timescales required to develop hypertension from chronic xenobiotic exposure, toxicological studies need to focus on early events in the development process to predict the risk of onset as long-term clinical/ epidemiological studies may not be practical for timely and cost-effective risk assessment.

One of the most widely reported hypertension risk factors is tobacco smoking. While smoking cessation remains the best way to reduce the harmful effects of tobacco smoking, tobacco harm reduction is being considered by some regulators (e.g., US Food and Drug Administration [FDA]) as a complementary strategy to reduce smoking-related disease burden. The US FDA has published guidance on assessing a modified risk tobacco product, either through demonstration of reduced toxicant exposure or reduction in health risks. ${ }^{6}$ By gaining an understanding of how, and to what extent, tobacco smoke initiates biological mechanisms of hypertension, such knowledge could be utilized as a baseline for comparison purposes in toxicological assessments of the risk reduction potential of e-cigarettes.

Given the wide variety of data requirements to support such risk assessments, for example, human exposure studies, behavioral studies, efficacy studies, in vitro studies, clinical biomarker studies, pharmacokinetic studies, quality of life studies, a data integration framework is required to organize these data types into a comprehensive story that (i) characterizes the toxicological problem, (ii) demonstrates the likely outcome of an intervention, and (iii) can be utilized to monitor the performance of any intervention over time. Adverse outcome pathways (AOPs) offer scientists and regulators such a vehicle.

In this article, we briefly describe the principles of AOP development and present the supporting information, which substantiates a proposed AOP for hypertension through a mechanism of endothelial cell oxidative stress. We believe that such an AOP would be of benefit for both toxicological risk assessment purposes and for monitoring efficacy of therapeutics that aim to treat or protect against the condition.

\section{AOP Development Process}

The AOP development process has been well described by Villeneuve et al. ${ }^{7}$ and Horvat et al. ${ }^{8}$ Briefly, the basic principles of AOP development require the author(s) to es- tablish a molecular initiating event (MIE), adverse outcome (AO), and a series of key events (KEs), which describe the critical intermediary steps in between the MIE and AO. Furthermore, KE relationships (KERs) are required to scientifically describe the mechanistic relationship between any two stated KEs, one of which is upstream and the other downstream. Thus, the status of the downstream KE should be able to be predicted or inferred by measurement of the upstream KE. By definition, AOPs are chemically agnostic and the AOP description should be independent from any specific chemical initiator and/or mode of action. ${ }^{7}$ However, this is not to say that experimental data using specific chemicals for the purposes of establishing mechanism and biological response patterns should be avoided; in fact, quite the opposite, such studies are critical in determining KE essentiality. Therefore, an AOP development process starts by identifying the compounds (or compound classes) that have been clinically proven to induce the particular AO of interest.

In this specific case, given that tobacco smoking is one of the major clinically proven risk factors for the development of hypertension, ${ }^{3}$ we have included information on compounds traditionally found in the aerosols of combusted organic matter, alongside known inducers of endothelial oxidative stress. A literature review was undertaken to map out the KEs for the purposes of weight of evidence assessment. By initially focusing on the AO and working backward through progressively lower levels of biological organization, we could be sure that the KEs remained focused toward the AO. Hence, we applied a top-down strategy for the development of this AOP.

KEs have been defined as changes in biological state, which have to be both measurable and essential for the specific AO. ${ }^{8}$ Given the considerable complexity of the biology underlying hypertension, it is tempting to define as many inter-related pathways as possible to provide a comprehensive overview. However, an AOP does not provide a comprehensive molecular description of every aspect of the biology involved, but focuses on the critical steps in the pathway, which are essential for the progression of AOP toward the AO. Ideally, AOPs are simplified pragmatic frameworks, which are linear in nature and connect a single MIE to a single AO by means of nonbranching and directional sequences of KEs. We have tried to adhere to these principles as much as possible where the biology allowed, in our proposed AOP, for oxidative stress-induced hypertension. The following information in this article will substantiate the AOP according to the guidelines laid out in the Organisation for Economic Cooperation and Development (OECD) AOP handbook. ${ }^{9}$ Supporting evidence for KERs is presented and evaluated according to three principles, namely biological plausibility of the KEs (most important), biological essentiality of the KEs, and quantitative evidence of the KERs (least important). We have assessed the relative strength of each of these KERs according to modified Bradford-Hill criteria, ${ }^{10}$ as suggested by the OECD handbook.

\section{AOP MIE, KEs, and AO}

A summary schematic of the AOP is presented in Figure 1. Further information on this AOP is presented online at the OECD AOPwiki site: https://aopwiki.org/aops/149 


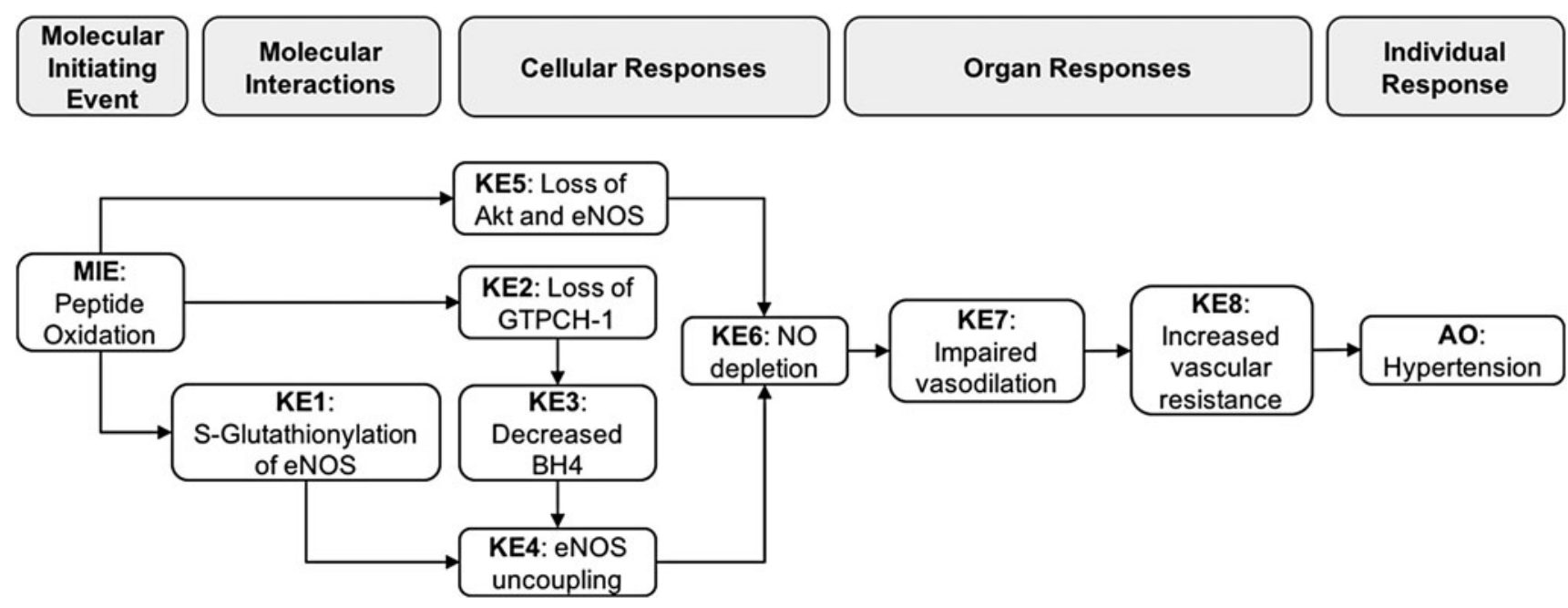

FIG. 1. Schematic of the adverse outcome pathway, linking peptide oxidation to hypertension. MIE, molecular initiating event; KE, key event; AO, adverse outcome; eNOS, endothelial nitric oxide synthase; AKT, protein kinase B; GTPCH-1, guanosine triphosphate cyclohydrolase 1; NO, nitric oxide; $\mathrm{BH} 4$, tetrahydrobiopterin.

\section{Molecular initiating event}

The MIE of this AOP is peptide oxidation within endothelial cells lining the circulatory vasculature. The rationale for this is due to the broad (yet critical) effects of oxidation on the downstream target molecules in the AOP, which ultimately culminate in reduced endothelial nitric oxide (NO) bioavailability (forstermann, whitsett piclo). ${ }^{11,12}$ Peptide oxidation within endothelial cells can arise as a result of endothelial oxidative stress, which can occur following exposure to a direct oxidant(s) or through xenobiotic exposure leading to the generation of secondary oxidants, for example, reactive oxygen (ROS) nitrogen species by intracellular processes. $^{12-14}$ Intracellular antioxidant peptides such as reduced glutathione (GSH) act as scavenger molecules to limit oxidative damage to critical biomolecules such as DNA, proteins, and lipids. ${ }^{15,16}$ As intracellular antioxidant protection is overwhelmed by increasing levels of oxidative species, antioxidant depletion occurs, which in turn can lead to protein/lipid oxidation. ${ }^{15-17}$ A wide range of chemicals are capable of causing MIE as any chemical exposure, which causes a shift in the redox balance of vascular endothelial cells toward oxidation (oxidative stress), can theoretically lead to MIE. Given the sealed nature of the circulatory system and high reactivity of oxidative radicals, vascular oxidative stress tends to arise from secondary generation of oxidant species following the action of xenobiotics and/or dietary and lifestyle factors, as opposed to exposure to direct acting oxidants, which are more likely to react with more proximal tissues related to the route of exposure. ${ }^{18-20}$ Known secondary oxidant species include superoxide, peroxynitrite, hydroxyl radicals, lipid/protein peroxides, and carbonyls. ${ }^{21}$ In vitro studies in endothelial cells have shown that exposure to chemicals, such as hydrogen peroxide, tertbutyl hydroperoxide, glucose, ultrafine particles (UFPs) derived from ambient air, 4-hydroxynonenal (4-HNE), and methylglyoxal, lowers the intracellular GSH content of human umbilical vein and pulmonary aortic endothelial cells. ${ }^{12,22-26}$

Measurement of GSH itself and the GSH:GSSG ratio within endothelial cells can be achieved by the use of commercially available luminescence-based assays on the cellular lysates. Measurement of specific oxidative modification of target proteins can be achieved by immunoblotting techniques. 27,28

\section{KE1: S-glutathionylation of endothelial nitric oxide synthase}

Oxidation of GSH results in the formation of a disulfidebridged glutathione dimer (GSSG). GSSG is either rapidly rereduced back to GSH by nicotinamide adenine dinucleotide phosphate (NADPH)-dependent GSSG-reductases or extruded from the cell by adenosine triphosphate-dependent translocases. However, when these mechanisms become overwhelmed by high local oxidant concentrations, GSSG can interact with protein thiol groups to form protein-GSSG adducts, a process termed S-glutathionylation. ${ }^{29}$ Interestingly, glutathione disulfide protein formation has been suggested to occur with a certain degree of specificity to cellular proteins since protein thiol groups exhibit considerable heterogeneity in terms of their individual $\mathrm{pK}_{\mathrm{a}}$ values and their location in protein structures. ${ }^{29}$ The oxidation of GSH to GSSG elevates levels of GSSG, which then covalently bind to critical serine residues on endothelial nitric oxide synthase (eNOS). ${ }^{22,27,30}$

Measurement of KE1 can be achieved as described above by immunoblotting techniques on endothelial cell lystates, ${ }^{27,28}$ and also through mass spectrometry analysis of eNOS protein-SG adducts. ${ }^{28}$

\section{KE2: loss of guanosine triphosphate cyclohydrolase-1}

GTPCH-1 converts GTP to 7,8-dihydroneopterin triphosphate and is the rate-limiting enzyme responsible for the production of 5,6,7,8-tetrahydrobiopterin (BH4) in a three-step process within endothelial cells. ${ }^{31}$ Loss of enzyme activity leads to depletion of cellular BH4 within endothelial cells.

Measurement of KE2 can be achieved in cell lysates using immunoblotting as described by Wang et al., ${ }^{32}$ also GTPCH-1 ELISA kits are commercially available.

\section{KE3: decreased $\mathrm{BH} 4$}

$\mathrm{BH} 4$ is a critical cofactor of eNOS, which facilitates the production of NO. ${ }^{31,33}$ Oxidative stress-related $\mathrm{BH} 4$ depletion 
occurs primarily by two mechanisms: (1) by oxidation of GTPCH-1, the rate-limiting enzyme responsible for BH4 production; or (2) by oxidation of $\mathrm{BH} 4$ itself by other oxidant species. As already described, BH4 is synthesized from guanosine triphosphate in a three-step process, in which the first step, mediated by GTPCH-1, is the rate-limiting step. ${ }^{31}$

Measurement of KE3 can be achieved both in cellular lysates and supernatants, also in plasma. Analysis is through high-performance liquid chromatography, and its oxidized form ( $\mathrm{BH} 2)$ is commonly measured in tandem to give a ratio of the two analytes. This method is described by Biondi et al. ${ }^{34}$

\section{KE4: eNOS uncoupling}

eNOS is the primary enzyme responsible for the production of NO in the vascular endothelium. ${ }^{35}$ eNOS is a modular enzyme, which contains a C-terminal reductase domain (which binds NADPH, flavin mononucleotide, and flavin adenine dinucleotide) linked to an N-terminal oxygenase domain (which binds 1-arginine, molecular oxygen, and $\mathrm{BH} 4$ ). L-arginine is converted into 1-citrulline, with NO produced as a byproduct. $^{35}$ The net result of KEs 1, 2, and 3 is the uncoupling of the eNOS enzyme, in which eNOS retains its NADPH oxidase function and produces superoxide, but loses the ability to produce NO. ${ }^{22,27,30,36}$

Measurement of KE4 can be achieved through the use of redox-sensitive probes such as dihydroethidium and hydroethidine, which form oxidation products with the superoxide that is liberated from uncoupled eNOS. The abundance of oxidation products is measured through HPLCs, and a detailed method was described by Zhao et al. ${ }^{37}$ Furthermore, detailed methods for EPR spin trapping of superoxide using DMPO/ BMPO have been published. ${ }^{28,38}$

\section{KE5: loss of AKT and eNOS}

The predominant signaling pathway leading to activation of eNOS (by phosphorylation) is also perturbed by oxidative stress. The phosphatidylinositol 3-kinase (PI3K)-AKT pathway is responsible for the phosphorylation of human eNOS at the serine 1177 residue. ${ }^{39,40}$ There are also an increasing number of hormones or bioactive substances found to modulate eNOS function through the PI3K/AKT pathway. These include insulin, insulin-like growth factor, angiopoietin-1, estrogen, leptin, sphingosine 1-phosphate, vascular endothelial growth factor, ROS, and corticosteroids. ${ }^{41}$ Thus, phosphorylation of human eNOS serine 1177 by AKT is a central mechanism of eNOS regulation and NO production. ${ }^{42-44}$ Oxidative damage to these enzymes by radical species results in both loss of enzyme function and decreased enzyme levels. ${ }^{45,46}$

Measurement of KE5 can be achieved in cellular lysates through immunoblotting techniques and commercially available ELISA kits. It is recommended that the phosphorylation status of enzymes is measured (also by immunoblotting/ ELISA) in addition to total enzyme to provide information on the activation status.

\section{KE6: NO depletion}

NO is a critical endothelium-derived hyperpolarizing factor, responsible for relaxation of vascular smooth muscle and vasodilation. The primary regulator of endothelial vasodilator function through NO is vascular shear; the frictional force exerted on the vascular wall during the flow of blood through the vessel. Vascular shear opens calcium channels on endothelial cells and leads to the calcium-dependent activation of eNOS and thus NO production. NO then diffuses to the underlying vascular smooth muscle, where it activates soluble guanylate cyclase, causing an increase in cyclic guanosine monophosphate, potassium ion efflux, hyperpolarization, and smooth muscle relaxation. ${ }^{47}$ Depletion of vascular NO bioavailability causes an imbalance in the maintenance of vascular tone, which shifts in favor of vasoconstriction, and hence elevates blood pressure (BP). ${ }^{48}$

Measurement of KE6 can be achieved both directly by measurement of NO itself through EPR spectrometry ${ }^{30}$ or indirectly using chemiluminescence methods. Kapuganti et al. describe various chemiluminescence methods and provide comments on the advantages and disadvantages of their use. ${ }^{49}$

\section{KE7: impaired vasodilation}

Vasodilation and its various modulating stimuli are well described by Giles et al. ${ }^{47}$ Vascular tone decreases during vasodilation, increasing the size of vessel lumen as the underlying vascular smooth muscle relaxes. Impairment of vasodilation can arise as a result of perturbation of the key vasodilatory mechanisms, which includes NO bioavailability. Impairment is characterized by narrowing of the vessel lumen and stiffening of the vessel due to increased vasoconstriction.

This KE can be quantified by measuring isometric tension using ex vivo tissues (for example, aortic rings or sections of other relevant arterial tissue) as described by Dhar et al. ${ }^{23}$ In live animals and human subjects, flow-mediated dilatation (FMD) (usually of the branchial artery in humans and femoral artery in rodents) through B-mode ultrasound is routinely used and is well described by Raitakari and Celermajer. ${ }^{50}$

\section{KE8: increased vascular resistance}

Vascular resistance is the resistance that must be overcome to push blood through the circulatory system and create flow. The resistance offered by the systemic circulation is known as the systemic vascular resistance (SVR) or may sometimes be called by the older term-total peripheral resistance (TPR). $\mathrm{BP}$ is commonly described as a function of cardiac output and vascular resistance. Although a simplification, this emphasizes that an elevation of mean BP can only come about as a result of an increase in cardiac output, an increase in vascular resistance, or a combination of both. ${ }^{51}$

Measurement of this KE can be achieved noninvasively as described by Stefadouros et al. ${ }^{52}$

\section{Taxonomic applicability/species concordance and other considerations}

With respect to the MIE, GSH-mediated oxidant scavenging is highly conserved in both plants and animals. ${ }^{53,54}$ Differences with respect to how GSH is generated/recycled through enzymatic pathways could differ, however. Similarly, amino acid (AA) oxidation within proteins occurs throughout the plant, animal, and bacterial kingdoms.

The biology of KEs 1-6 is likely to be conserved across mammalian species. This is specifically evident from the numerous studies utilizing bovine, rodent, and human endothelial cells in vitro, rodent in vivo models of hypertension, and human clinical studies, in which the KERs follow the same 
biology. (De)phosphorylation sites specifically for eNOS (de)activation are conserved between cows, mice, and humans. ${ }^{55-57}$ Therefore, oxidation of these specific AA residues is likely to show similar effects on eNOS function and NO bioavailability (although the magnitude may vary). While the overall function of AKT, eNOS, and GTPCH-1 is conserved in mammalian species, the effect of oxidation/ modification of other AA residues on the function of these enzymes has not been sufficiently characterized and hence differences are possible.

The biology of KEs 7 and 8 and KERs KE7 $\rightarrow$ KE8 and $\mathrm{KE} \rightarrow \mathrm{AO}$ is highly complex, and numerous sex, age, tissue, and species differences are evident, also between healthy and diseased animals and humans. Durand and Gutterman highlight such differences in great detail ${ }^{58}$ and we refer the reader to this article.

With respect to gender differences, Scotland et al ${ }^{59}$ noted differences in acetylcholine-induced vasodilatory responses in C57/BL6 mice, in which vasodilation in male mice was abolished with eNOS blockade alone, whereas female mice required both eNOS and COX blockade to observe the same effect. Therefore, it is possible that mechanisms of vasodilatory plasticity could differ between males and females. Although some of the evidence presented in this article is derived specifically from males or females, the processes described are applicable to both genders. This is corroborated by epidemiological data, which indicate that hypertension affects women and men from age 45 to 64 years nearly equally. ${ }^{3}$

To conclude this subsection, the support for the proposed AOP combines well-documented in vitro evidence from multiple organisms, including mouse, rat, cow, and humans. However, the current view relates these differences to changes in physiological status or to age-related comorbidities such as obesity and type II diabetes, which are also linked to increased oxidative stress. ${ }^{60}$ While eNOS-mediated NO signaling clearly plays a key role in the development of hypertension (see Empirical Evidence Supporting KERs), other compensatory mechanisms are capable of maintaining vascular tone in the short-medium term. However, the specific mechanisms of these compensatory changes in humans over the longer term are poorly understood and hence require further study.

\section{Empirical Evidence Supporting KERs}

\section{MIE (peptide oxidation) to KE1} (S-glutathionylation of eNOS)

Hypoxia/reoxygenation-induced oxidative stress (associated with ischemia/reperfusion injury) was shown to deplete GSH in bovine aortic endothelial cells, which led to Sglutathionylation of eNOS and eNOS uncoupling. This phenomenon was partially reversible, in bovine aortic endothelial cells and rat aortic rings, by raising intracellular GSH levels upon administration of $\mathrm{N}$-acetylcysteine. ${ }^{23,27}$

Chen et al. have shown that eNOS is particularly sensitive to S-glutathionylation at cysteine residues 689 and 908 of the reductase domain, a phenomenon that is dose dependent with application of exogenous GSSG. ${ }^{30}$ This finding was corroborated by Peng et al. using mutated eNOS constructs in Escherichia coli, demonstrating that superoxide was produced by the eNOS phosphorylation site in the reductase domain. ${ }^{61} \mathrm{Wu}$ et al. studied responses in human lung microvascular endothelial cells to lipopolysaccharide (LPS) in vitro. Upon LPS ad- ministration, NADPH oxidase 2 (NOX2) expression levels increased with a subsequent rise in superoxide production, which led to S-glutathionylation of eNOS. ${ }^{62}$ Furthermore, in mice, coimmunoprecipitation studies revealed that NOX2 associated with eNOS and that S-glutathionylation in response to LPS was much more apparent in elderly animals compared with younger animals. ${ }^{62}$ Similar observations were made by De Pascali et al. following hypoxia-induced oxidative stress in bovine aortic endothelial cells. ${ }^{27}$ Finally, Chen et al. demonstrated that coadministration of glutaredoxin-1 and GSH reversed GSSG-mediated eNOS S-glutathionylation and restored eNOS-mediated NO production, also in bovine aortic cells. Interestingly, inhibition of eNOS function occurred when the GSH/GSSG ratio was $>0.2$ and function was restored at a ratio of $<0.1 .^{63}$

\section{MIE (peptide oxidation) to KE2 (loss of GTPCH-1)}

Although biologically plausible, based upon widely accepted existing knowledge that oxidative modification of protein AA residues can cause protein dysfunction, evidence specifically linking the MIE to KE2 is limited. 4-HNE is a carbonyl known to induce oxidative stress. Bovine aortic endothelial cells exposed to 4-HNE had reduced levels of GTPCH-1 compared with controls. Control experiments with cycloheximide (a protein synthesis inhibitor) confirmed that 4-HNE did not act to inhibit synthesis of GTPCH-1, but rather it damaged the protein and induced proteasomal degradation (confirmed by studies with proteasomal inhibitors). ${ }^{12}$ In murine lungs where localized vascular oxidative stress was induced by the selective depletion of endothelial superoxide dismutase (SOD), levels of active GTPCH-1 were shown to be reduced in the knockout animals compared with controls. ${ }^{64}$ Furthermore, in atrial samples from patients undergoing cardiopulmonary bypass surgery, NOX2 expression and superoxide production were elevated following tissue reperfusion (known to induce oxidative stress), with a corresponding 50\% reduction in GTPCH-1 activity and a $32 \%$ decrease in BH4. Although eNOS activity was significantly decreased by $\sim 60 \%$ following reperfusion, $\mathrm{BH} 4$ supplementation did not recover eNOS activity, whereas treatment with dithiothreitol reversed eNOS S-glutathionylation and restored eNOS activity. ${ }^{36}$ This final example is, however, a published abstract, and no follow-up publication could be found at the time of writing to permit scrutiny of the study.

\section{KE2 (loss of GTPCH-1) to KE3 (decreased BH4)}

With respect to KE essentiality, numerous studies have demonstrated that deletion of GTPCH-1 led to the deficiency of BH4 in bovine and murine endothelial cells ${ }^{31,33,65}$ and in knockout mice. ${ }^{28}$ Exposure of bovine or mouse aortic endothelial cells to GTPCH-1 inhibitors (DAHP or NAS) or GTPCH-1-siRNA significantly reduced $\mathrm{BH} 4$ and $\mathrm{NO}$ levels and increased superoxide levels. The increase in superoxide was abolished by the $\mathrm{BH} 4$ precursor sepiapterin. ${ }^{32}$ In vivo, gene silencing of GCH1 (the gene that codes for the GTPCH-1 enzyme) and GTPCH-1 inhibition lead to elevated BP in mice and rats. ${ }^{32,66}$ Furthermore, GTPCH-1 gene transfer into diabetic rats increased $\mathrm{BH} 4$ bioavailability and NO production. ${ }^{67}$

In C57/BL6 mice, gene silencing through siRNA of GTPCH1 reduced BH4 levels and raised BP compared with control animals and, furthermore, GTPCH-1 siRNA was unable to elicit these effects in eNOS null mice. Sepiapterin supplementation, 
which had no effect on high BP in eNOS $-/-$ mice, partially reversed GTPCH-1 siRNA-induced elevation of BP in wildtype mice. ${ }^{32}$ In another study, endothelial cells from diabetic rats were shown to have decreased expression of GTPCH-1, significantly reduced BH4 levels, and impaired NO synthesis compared with cells from normal animals and diabetes-prone animals, which did not develop disease. ${ }^{68}$ In a follow-up study by the same group, artificial restoration of BH4 with sepiapterin in diabetic rats increased $\mathrm{ACh}$-induced relaxation in the GTPCH-1-inhibited animals. ${ }^{67}$ Similarly, in diabetic wild-type mice, endothelial superoxide levels were elevated, with associated oxidation of $\mathrm{BH} 4$ to $\mathrm{BH} 2$ and impaired vasodilation. The importance of GTPCH-1 was evident when in contrast, a transgenic clone in which GTPCH-1 was overexpressed showed that superoxide levels were decreased and $\mathrm{BH} 4$ levels and NO-mediated vasodilation were maintained compared with wild-type animals. ${ }^{69}$ Inhibition of GTPCH-1 with 2,4diamine-6-hydroxypyrimidine in rats yielded a $30 \mathrm{mmHg}$ rise in BP compared with control rats. ${ }^{66}$ Overexpression studies showed that the rise in BP in mice with salt-sensitive hypertension and also in mice undergoing myocardial ischemia/ reperfusion injury was ameliorated by GTPCH-1. ${ }^{70,71}$ In hypertensive rats, clofibrate treatment was associated with activation of GTPCH-1, elevated BH4, and attenuation of hypertension. Correspondingly, superoxide and lipid peroxides were decreased in the same animals. ${ }^{72}$

In humans, BH4 supplementation was shown to reverse smoking-induced impaired vasodilation, ${ }^{73}$ improve endothelial function, and decrease arterial stiffness in estrogendeficient postmenopausal women ${ }^{74}$ and in older men. ${ }^{75}$

Furthermore, localized oxidative stress is generated during an intermediary step where uncoupled eNOS and coupled eNOS in the same locale produce superoxide and NO, respectively, which interact to form peroxynitrite and can further deplete $\mathrm{GSH}^{24}$ and perpetuate the condition. Endothelial cells treated with peroxynitrite exhibited reduced eNOS activity and disruption of eNOS dimers. ${ }^{76}$ In ApoE-deficient mice, peroxynitrite formation from uncoupled eNOS was shown to be primarily responsible for oxidation of $\mathrm{BH} 4$ to $\mathrm{BH} 2{ }^{77}$ Furthermore, $\mathrm{Li}$ et al. also state that the oxidized form (BH2) can compete with $\mathrm{BH} 4$ for eNOS interaction as they share the same binding domain. However, since $\mathrm{BH} 2$ cannot support eNOS coupling, this displacement results in eNOS uncoupling. Therefore, under oxidative stress conditions, BH4-dependent eNOS function is reliant upon recycling mechanisms and de novo synthesis of BH4 by GTPCH- $1{ }^{78}$

\section{KE1 (S-glutathionylation of eNOS) and KE3} (decreased BH4) to KE4 (eNOS uncoupling)

eNOS uncoupling is a phenomenon where the reductase domain and the oxygenase domain of the enzyme are no longer held together in an active dimer. BH4 is a highly redoxsensitive eNOS cofactor, which promotes the coupling of both domains, leading to efficient production of NO.79,80 Upon BH4 depletion, electron transfer from the C-terminal reductase domain to the $\mathrm{N}$-terminal oxygenase domain is blocked, resulting in production of superoxide, as opposed to NO. ${ }^{77}$ The molecular mechanisms of eNOS uncoupling have been extensively reviewed, with reduced $\mathrm{BH} 4$ bioavailability and S-glutathionylation of eNOS playing a critical role in the deleterious production of superoxide by uncoupled eNOS. ${ }^{81-83}$
It has been demonstrated in vivo and in vitro that eNOS is uncoupled when $\mathrm{BH} 4$ bioavailability is limited. The mechanism leading to BH4 depletion is generally attributed to oxidation of BH4 by ROS and/or peroxynitrite (the product of the chemical reaction between $\mathrm{NO}$ and superoxide), and supplementation with $\mathrm{BH} 4$ has been reported to restore eNOS activity. ${ }^{84-87}$ De Pascali et al. demonstrated the onset of eNOS uncoupling in vitro, which was due to a combination of Sglutathionylation of eNOS protein and reduced $\mathrm{BH} 4$ bioavailability. ${ }^{27}$ Elevation of intracellular GSH by administration of $\mathrm{N}$-acetylcysteine and coadministration of exogenous BH4 reversed hypoxia/reoxygenation-induced eNOS uncoupling. These findings were supported by Crabtree et al. in murine fibroblasts expressing mutated eNOS. ${ }^{88}$ The authors concluded that both S-glutathionylation and BH4 deficiency-although functionally related-were mechanistically distinct events. However, a study in atrial tissue from human subjects demonstrated that eNOS activity was only restored following reversal of eNOS S-glutathionylation, while BH4 supplementation had no effect ${ }^{36}$ (abstract only).

\section{MIE (peptide oxidation) to KE5 (loss of AKT and eNOS)}

eNOS activity was reduced by several stressors (methylglyoxal, high glucose, SIN-1, hydrogen peroxide, cigarette smoke) in human and bovine endothelial cells, resulting in increased ROS and decreased eNOS activity. ${ }^{23,30,44,89,90}$ Exposure of endothelial cells to CSEaq has been shown to induce oxidative stress, inhibit AKT/eNOS phosphorylation, and decrease production of NO. ${ }^{45,91}$ Oxidative stress was shown to derive from increased intracellular ROS production following CSEaq exposure, which inhibited eNOS activity and was reversible by $\mathrm{N}$-acetylcysteine, a known ROS scavenger. ${ }^{91}$

\section{KE4 (eNOS uncoupling) and KE5 (loss of AKT and eNOS) to KE6 (NO depletion)}

Taken together, the KEs leading to eNOS uncoupling and the loss of AKT/eNOS activity collectively led to a decrease in NO bioavailability. Multiple experiments demonstrated that eNOS uncoupling results in increased superoxide formation and decreased NO production in vitro with bovine aortic endothelial cells ${ }^{27,30,32}$ and isolated mouse aortas. ${ }^{12,32,76,85}$ Various stress inducers (ischemia, peroxynitrite, SIN-1, insulin, uric acid, orotic acidura, etc.) showed that a decrease in Akt and/or eNOS activity led to decreased NO in bovine, rat, and human endothelial cells and rat aortic rings. ${ }^{23,85,89,92-94}$

While many studies support KERs KE4>KE6 and KE5 $>$ KE6, studies also support the fact that secondary oxidative stress generated by superoxide production, as a result of eNOS uncoupling and subsequent peroxynitrite formation, can also lead to loss of eNOS activity and NO depletion. Exposure of human aortic endothelial cells to UFP of $<200 \mathrm{~nm}$, commonly found in airborne pollution, significantly reduced NO production. UFP-mediated reduction in NO production was restored in the presence of the NADPH oxidase inhibitor apocynin (indicating the presence of uncoupled eNOS), N-acetyl cysteine, and SOD mimetics (Tempol and MnTMPyP). The depletion of NO was associated with an increased GSH/GSSG ratio and eNOS S-glutathionylation, whereas overexpression of glutaredoxin-1 (which reverses S-glutathionylation of eNOS in the presence of GSH) attenuated the UFP- 
mediated reduction in NO production by nearly $80 \%$, compared with overexpression of the LacZ control gene. ${ }^{22}$ Given that the restoration by glutaredoxin-1 was partial, it is possible that oxidative damage to AKT and eNOS itself could account for the remaining NO production. This was specifically confirmed by Zou et al. who demonstrated a reduction in AKT phosphorylation, AKT activity, AKT-dependent eNOS phosphorylation, and eNOS activity following increasing concentrations of peroxynitrite (formed from uncoupled eNOS and NO) in bovine aortic endothelial cells. ${ }^{76}$ Similar results were reported by Das et al. in the same cells utilizing SIN-1 as a source of peroxynitrite and the spin trap DMPO to recover eNOS function. ${ }^{89}$

\section{KE7 (NO depletion) to KE8 (impaired vasodilation)}

In vivo, eNOS knockout mice develop hypertension, with mean arterial BP values that are $20-30 \mathrm{mmHg}$ greater than values observed in wild-type animals, and such models are routinely used as models for the study of hypertension. ${ }^{95}$ Aortic rings from eNOS mutant mice do not relax in response to acetylcholine, but function normally upon application of NO donors such as sodium nitroprusside (SNP). These results confirm a role for basal eNOS activity in BP regulation and vascular tone. ${ }^{96}$

Du et al. showed that wild-type C57BL/6J mice fed a highfat diet developed hypertension. ${ }^{42}$ The aortic tissue harvested from these animals showed elevated expression of NOX2 and increased superoxide generation (confirmed by SOD ablation). Application of L-NG-nitroarginine methyl ester (L-NAME; a known inhibitor of eNOS) resulted in $20 \%$ reduction in superoxide production, indicating that most of the superoxide production originated from sources other than eNOS, such as NOX2 and other isoforms, but that uncoupled eNOS also contributed to the local superoxide levels. The elevated superoxide reduced phosphorylation of AKT and eNOS and impaired endothelial-dependent relaxation to acetylcholine (eNOS specificity confirmed by L-NAME coadministration). Superoxide was further implicated as a causal factor, in that application of an SOD mimetic restored acetylcholine-mediated vasorelaxation. In contrast, NOX2 knockout animals, animals treated with apocynin (an NOX2 inhibitor and ROS scavenger), and wild-type chow-fed animals showed none of these deleterious effects. ${ }^{42}$ Scotland et al. studied the effects of various agonists and antagonists of vasodilation in the mesenteric resistance arteries of eNOS and cyclooxygenase 2 (COX-2) double knockout C57BL/6 mice. They reported that pharmacological blockade of eNOS and COX-2 individually had no effect on vasodilation, whereas coadministration of antagonists impaired vasodilation, and female mice developed hypertension. This was in contrast to male mice, in which acetylcholine-mediated vasodilation was abolished by eNOS blockade alone, inducing hypertension. The data indicate that gender differences could play an important role in vascular aging due to the increased importance of prostaglandin $\left(\mathrm{PGI}_{2}\right)$ signaling in females. ${ }^{59}$

Studies with aortic rings from hyperuremic rats showed that insulin-induced vasodilation was impaired relative to control animals treated with allantoxanamide ( uricase inhibitor). Furthermore, the hyperuremic animals developed hypertension, whereas animals treated with allopurinol to lower serum uric acid levels did not. Complimentary studies in HUVECs treated with increasing concentrations of uric acid confirmed that the in vivo effects were mediated by a corresponding decrease in PI3K/AKT/eNOS phosphorylation and reduced bioavailability of $\mathrm{NO}^{92}$ Similar findings were published by the same group following induction of hypertension in rats treated with orotic acid. ${ }^{93}$

In humans, application of L-NAME and/or $\mathrm{N}^{\mathrm{G}}$-monomethylL-arginine (L-NMMA) resulted in elevated mean arterial pressure through impairment of NO-mediated vasodilation. Application of both drugs compounded the effect. ${ }^{97}$ A study in chronic smokers showed that smoking impairs FMD compared with nonsmoking subjects, respectively $(5.6 \% \pm 3.0 \%$ vs. $8.1 \% \pm 3.7 \% ; p<0.01)$, administration of $\mathrm{BH} 4$ improved FMD in both cohorts $(6.6 \% \pm 3.3 \%$ vs. $9.8 \% \pm 3.2 \% ; p<0.01)$, and smoking cessation for 1 week also improved FMD (from $5.0 \pm 2.9$ to $7.8 \% \pm 3.2 \% ; p<0.01$ ). These data indicate that improvement in arterial vasodilation was partially improved by BH4 administration. ${ }^{98}$ Another study in which current smokers switched to an e-cigarette product for 1 week showed significant reductions in FMD impairment compared with baseline, which was associated with improvement in levels of 8 -iso-prostagladin F2 $\alpha$ (a biomarker of oxidative stress). ${ }^{99}$

\section{KE8 (impaired vasodilation) to KE9 (increased vascular resistance)}

Reduction in blood vessel NO bioavailability has been reported to increase arterial BP in rat aortic rings and mesenteric arteries, mice, rabbits, and humans by a mechanism of impaired vasodilation. ${ }^{100-106}$ Where vasodilation is a key factor underlying vascular tone, impaired vasodilation leads to increased vascular resistance as the balance of vascular tone is shifted toward vasoconstriction. ${ }^{5}$ SVR or TPR is the resistance against which the heart must pump to maintain blood tissue perfusion. Treatment with eNOS inhibitor L-NGmonomethyl arginine citrate (L-NMMA) caused an increase in SVR and a reduction in NO in human subjects, ${ }^{102,104,107-109}$ while L-NAME decreased NO-dependent relaxation and increased BP in rats. ${ }^{102}$ In patients with malignant hypertension, treatment with the NO donor SNP, infused using a regimen in which dose was gradually increased to a maximum of $5 \mu \mathrm{g} /(\mathrm{kg} \cdot \mathrm{min})$, was reported to decrease mean arterial pressure by $\sim 28 \%$ and SVR by $\sim 53 \%$, indicating the potent effect of SNP (and NO) on systemic vasculature. Interestingly, the effects on cerebral vascular resistance were much less pronounced with $\sim 7 \%$ reduction in SV. ${ }^{110}$ Similarly, intravenous infusion of increasing doses of SNP was also shown to decrease SVR in a dose-dependent manner in patients with other cardiovascular complications. ${ }^{11-113}$

Impaired vasodilation and increased peripheral resistance are associated with vascular remodeling, arterial stiffening, and vascular aging, all of which are key contributors to the development of hypertension. ${ }^{114-116}$

\section{KE9 (increased vascular resistance) to $A O$ (hypertension)}

It is well established that increased vascular resistance contributes to the onset of hypertension through a mechanism of vascular remodeling and arterial stiffening over time, although the true extent is unknown. ${ }^{114-116}$

Several human studies showed a dose-dependent change in SVR and BP, following treatment with eNOS inhibitors. $^{32,101,103,107-109}$ In patients with hypertension, SVR was elevated in almost $66 \%$ of cases. ${ }^{117}$ It was reported that high normal BP $(130-139 / 85-89 \mathrm{mmHg})$ progresses to 


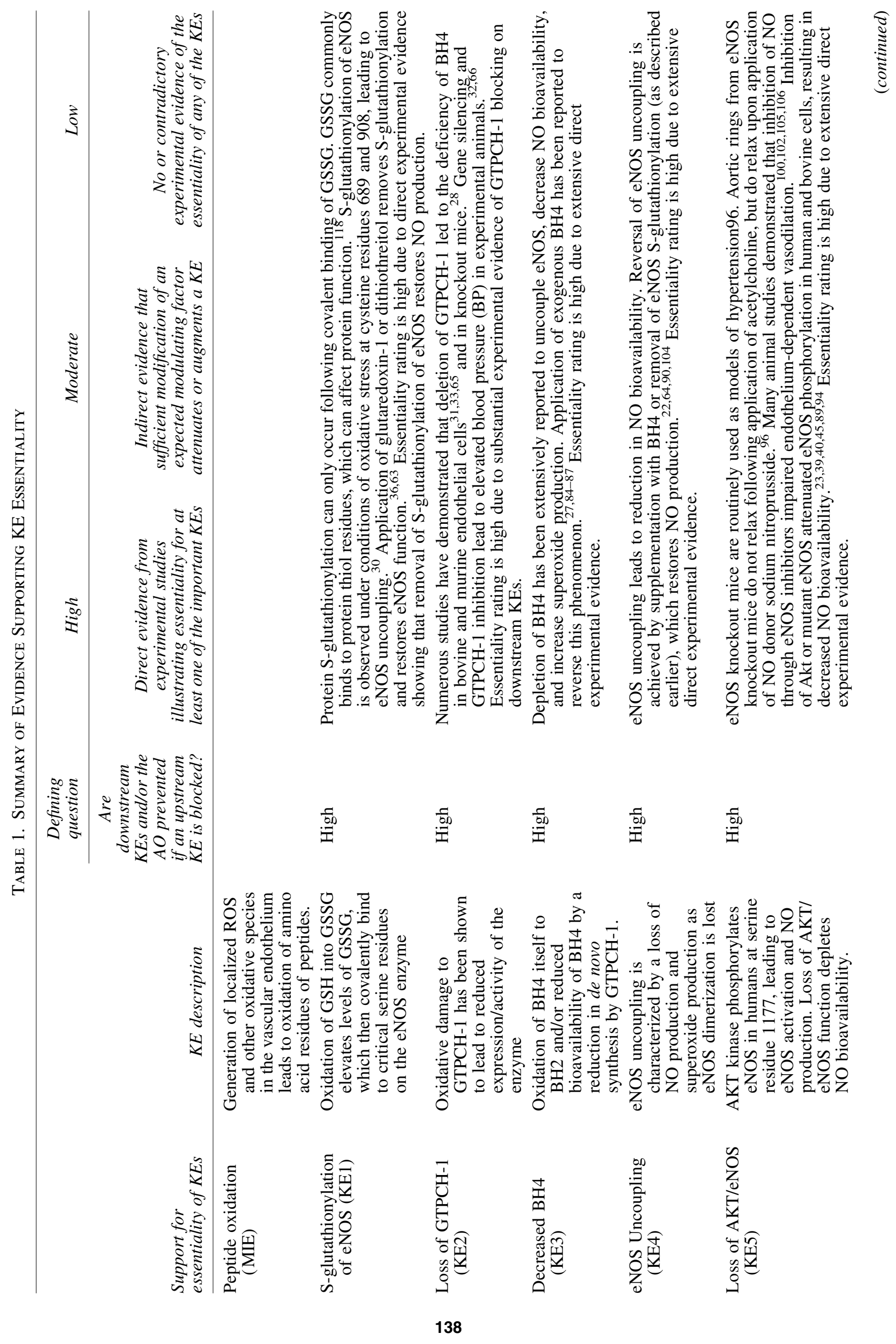




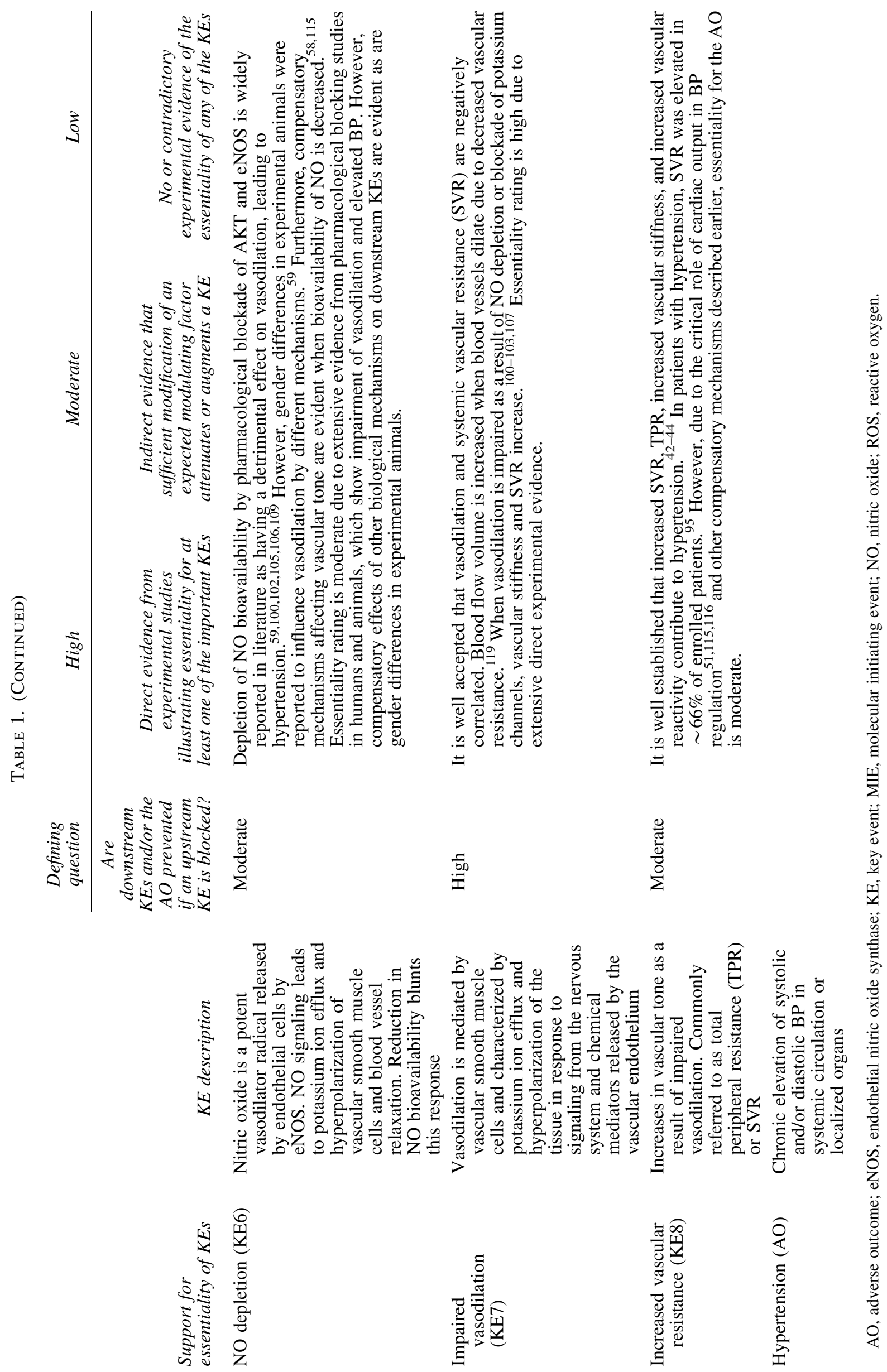




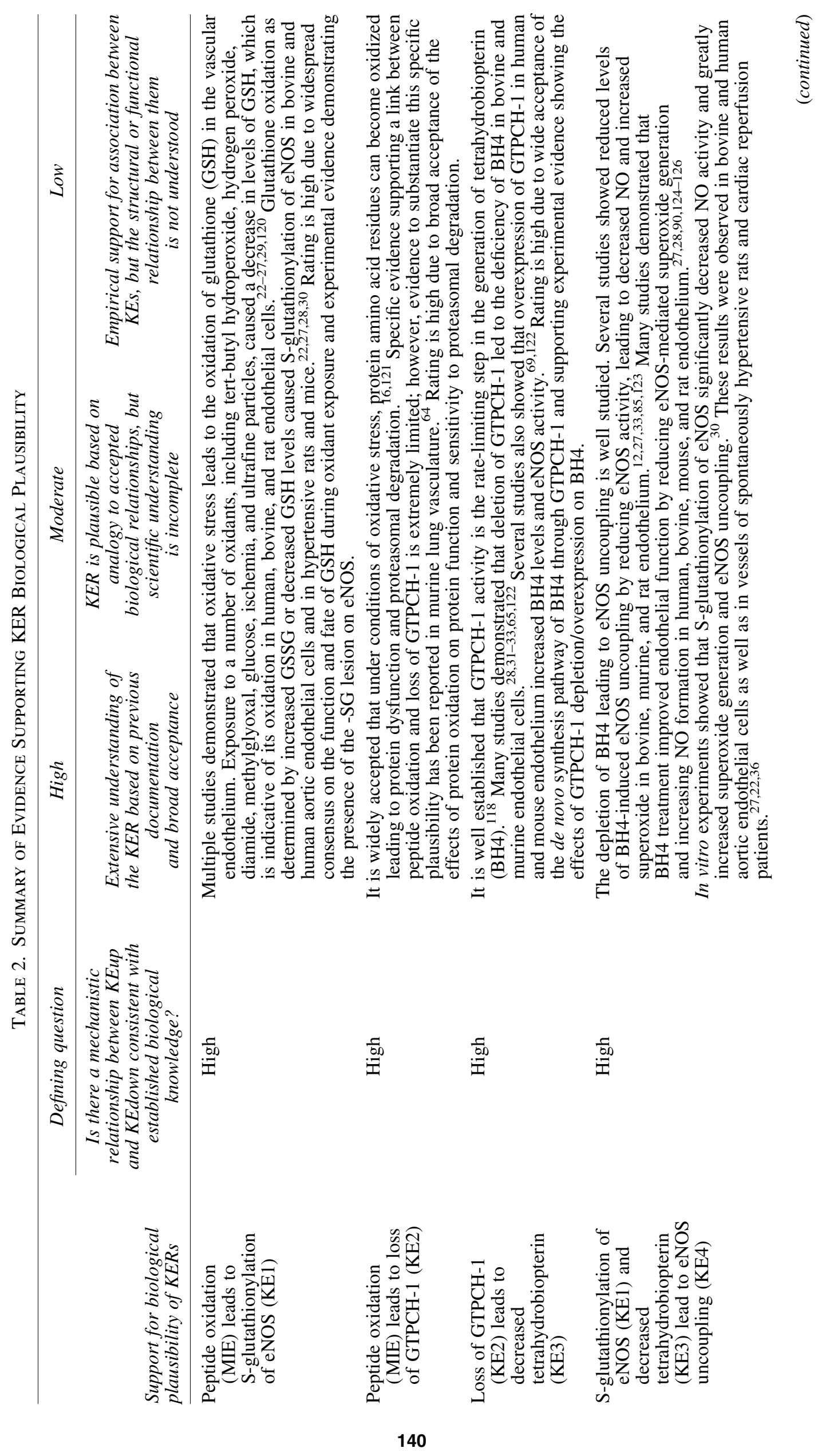




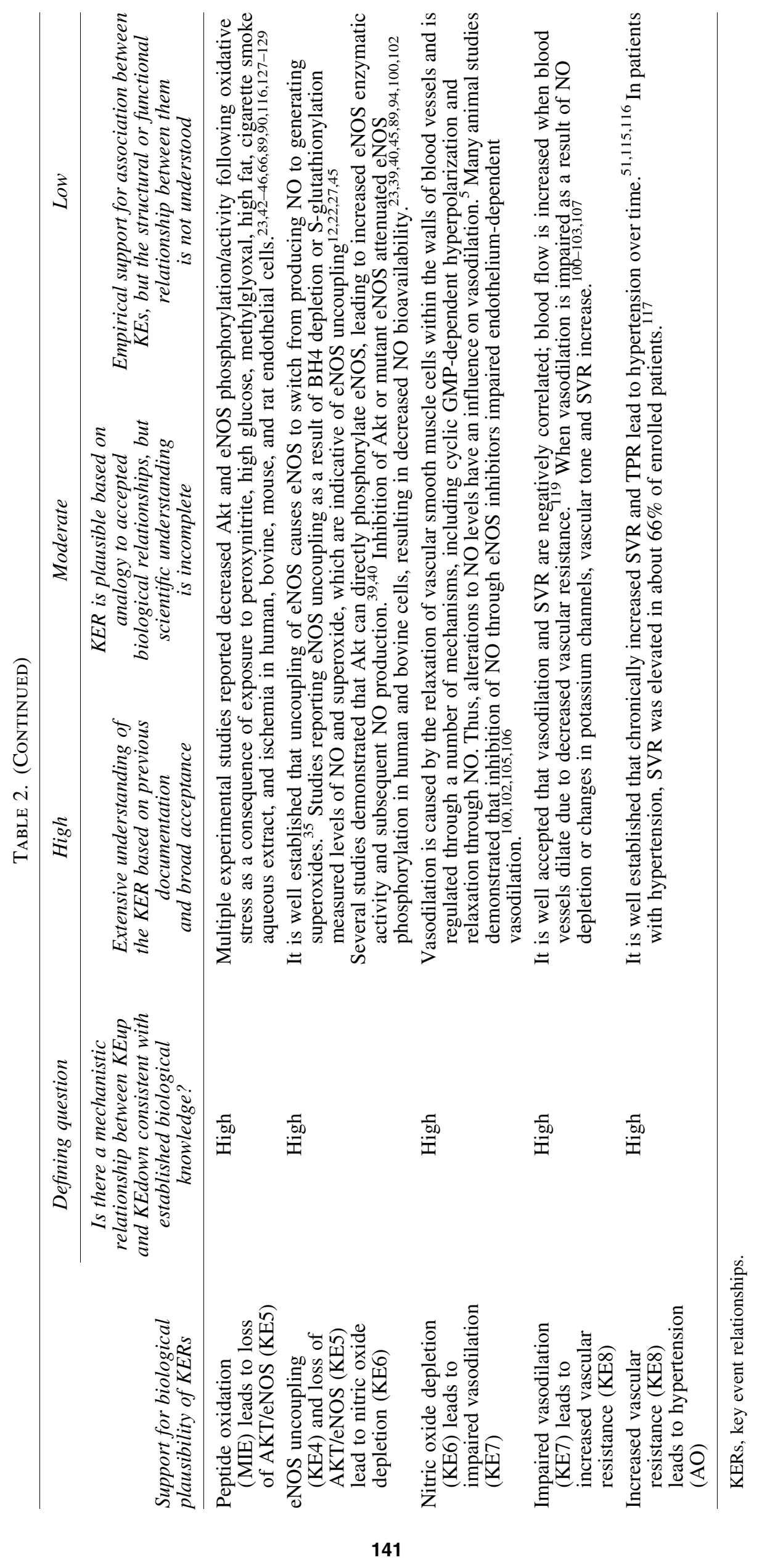




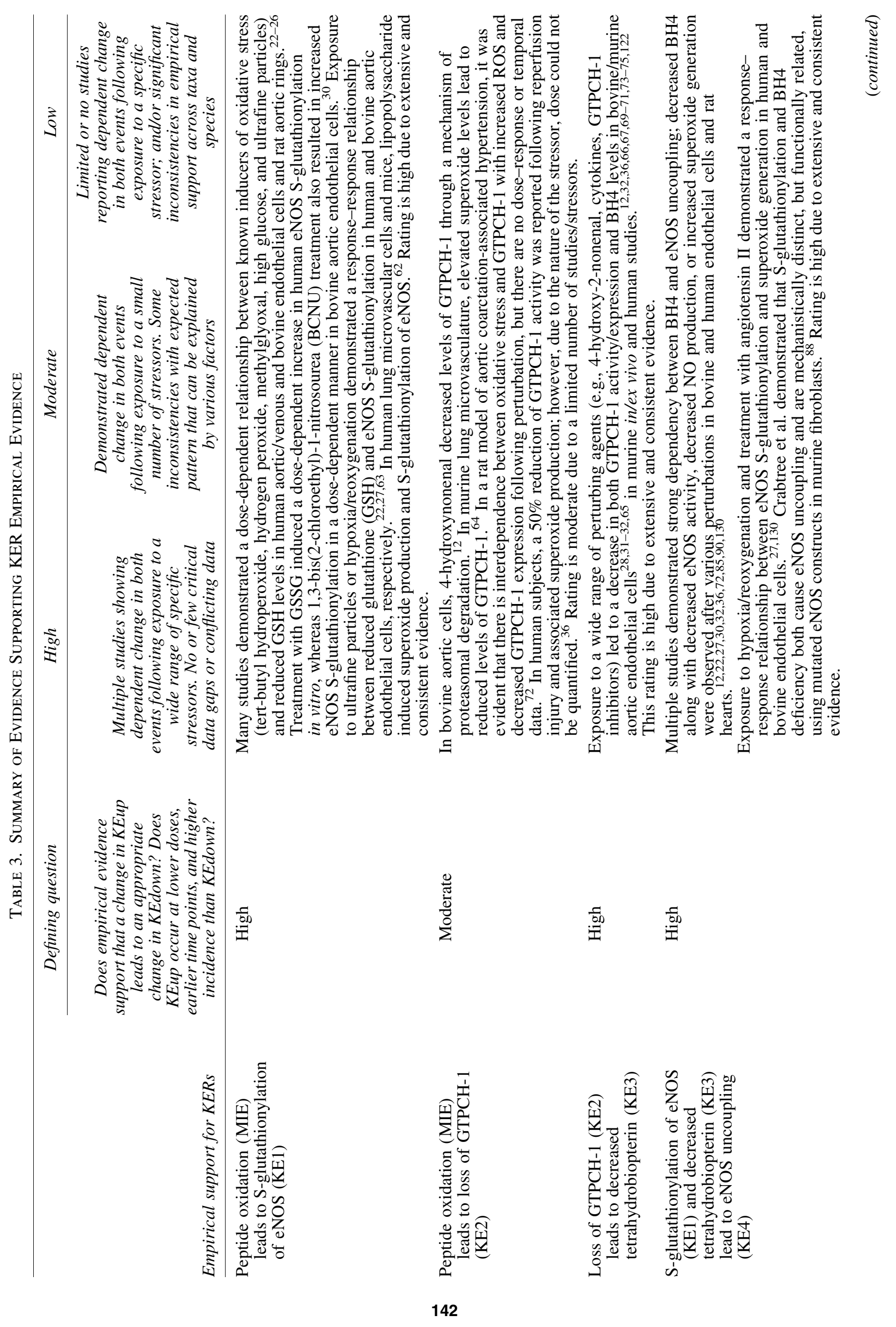




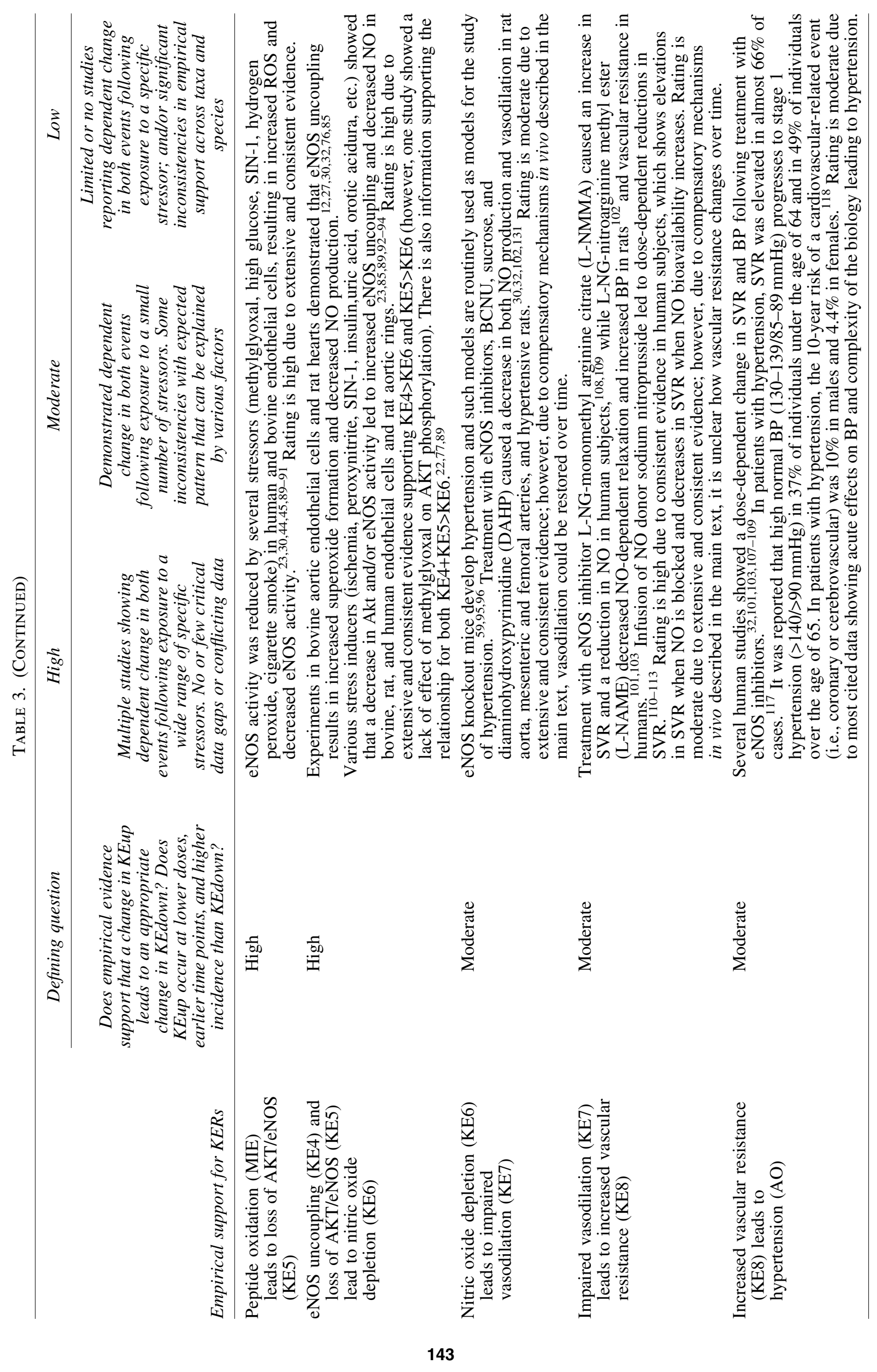


stage 1 hypertension $(>140 />90 \mathrm{mmHg})$ in $37 \%$ of individuals under the age of 64 and in $49 \%$ of individuals over the age of 65 . In patients with hypertension, the 10-year risk of a cardiovascular-related event (i.e., coronary or cerebrovascular) was $10 \%$ in males and $4.4 \%$ in females. ${ }^{116}$

\section{Overall Assessment of the AOP}

\section{KE essentiality}

Supporting evidence for KE essentiality, KER biological plausibility and empirical evidence are explained in detail in the subsections above and summarized in Tables 1-3, respectively. We rated essentiality as high for most KEs due to the existence of experimental evidence demonstrating that blocking them would prevent or attenuate the downstream KEs. KEs 7 and 9 were rated as moderate due to the influences of other major pathways/compensatory systems on downstream KEs discussed above.

\section{KER biological plausibility}

There is extensive published literature to support the biological plausibility of the KERs in vitro, in vivo, and from human clinical studies and the overall mechanisms are well understood. In light of this, we have rated the strength of all KERs as high, with respect to plausibility.

\section{KER empirical evidence}

Direct quantitative evidence supporting the KERs is lacking in some aspects of the AOP. However, many of the cited studies do measure multiple KEs in concert and evidence is derived by association of toxic effects and reversibility by chemical interventions to recover the pathway. For example, with respect to the KER MIE > KE1 while many studies demonstrate dosedependent glutathione oxidation in response to chemical stressors, studies which subsequently used GSSG specifically to induce eNOS S-glutathionylation are limited. The linkages are inferred by the use of chemicals, which induced $\mathrm{S}$ glutathionylation (hence derived from elevated intracellular GSSG, which was not measured), and investigated the effects of GSSG-eNOS adduct removal on downstream KEs. Similarly, the KER MIE to KE2 is rated as moderate due to the lack of quantitative chemical stressor data, although some consistent data are available. Supporting evidence is derived from the use of ischemia/reperfusion injury as a stressor, which does induce vascular oxidative stress, but cannot be quantified. KERs (KE6 > KE7), (KE7> KE8), and (KE8> AO) are also rated as moderate due to the possibility of interaction with compensatory pathways described earlier. Furthermore, the long-term effects of such mechanisms (for example, COXmediated prostaglandin and hydrogen peroxide compensatory vasodilation) are not well understood over years of life. Ratings and justifications are also shown in Table 3.

\section{Conclusion}

In summary, the weight of evidence for a role of each of the KEs described in this AOP and their inter-relationships in the development of hypertension over time are strong. However, as Brandes states, "to assume that endothelial vasodilator release through an increase in peripheral resistance directly translates into hypertension would be naïve". ${ }^{115}$ Hypertension is a very complex disorder, in which in addition to endothelial dysfunction, multiple organs/tissues (e.g., kidney, heart, brain, central/peripheral innervations, and blood vessel smooth muscle) and their associated chemical mediators also play a key role. That said, what is described here does represent the perturbation of one of the most important protective mechanisms for the maintenance of healthy blood vessel function and systemic tissue perfusion by vascular oxidative stress. Where peptide oxidation is induced by chronic chemical exposure, either intentional or otherwise, is of toxicological significance for regulatory purposes. The efficacy of health-promoting/harm-reducing interventions (e.g., health supplements), which purport to improve vascular health and alternatives to commonly used consumer products (e.g., smokers switching from combustible cigarettes to electronic cigarettes), could be assessed by using an integrated testing strategy built upon the foundations of this AOP. Finally, from the ethical perspective, the evidence presented to support this AOP demonstrates that the KEs can be measured using in vitro test systems and human clinical data in concert. While existing animal data remain an important resource to support the weight of evidence assessment of the AOP, the wealth of in vitro and human data presented in this article suggest that future testing strategies focused on nonanimal test systems are achievable.

\section{Acknowledgments}

The authors wish to thank Ruth Dempsey and Christopher Proctor for their helpful discussions and critical review during the preparation of this manuscript.

\section{Author Disclosure Statement}

F.J.L., L.E.H., and M.G. are full-time employees of British American Tobacco (Investments) Ltd. K.L., M.T., and J.H. are full-time employees of Phillip Morris International. V.H. was employed at Selventa at the time this project was undertaken, and Selventa received financial compensation from PMI for their services. The authors declare no further conflicts of interest with respect to the research, authorship, and/or publication of this article.

\section{References}

1. Lonn E, Bosch J, Teo K, et al. The polypill in the prevention of cardiovascular diseases: Key concepts, current status, challenges, and future directions. Circulation 2010: 122;2078-2088.

2. Lloyd-Jones DM, Leip EP, Larson MG, et al. Prediction of lifetime risk for cardiovascular disease by risk factor burden at 50 years of age. Circulation 2006:113;791-798.

3. Mozaffarian D, Benjamin EJ, Go AS, et al. Executive summary: Heart disease and stroke statistics-2016 update: A report from the American Heart Association. Circulation 2016:133;447-454.

4. Chobanian AV, Bakris GL, Black HR, et al. Seventh report of the joint national committee on prevention, detection, evaluation, and treatment of high blood pressure. Hypertension 2003:42;1206-1252.

5. Silva BR, Pernomian L, Bendhack LM. Contribution of oxidative stress to endothelial dysfunction in hypertension. Front Physiol 2012:3;441.

6. Food and Drug Administration. Guidance for Industry Modified Risk Tobacco Product Applications. Draft Guidance. 
Silver Spring, MD, USA: Center for Tobacco Products. 2012. www.fda.gov/downloads/TobaccoProducts/GuidanceComplianceRegulatoryInformation/UCM297751.pdf (last accessed Aug. 26, 2015).

7. Villeneuve DL, Crump D, Garcia-Reyero N, et al. Adverse outcome pathway (AOP) development I: Strategies and principles. Toxicol Sci 2014:142;312-320.

8. Horvat T, Landesmann B, Lostia A, et al. Adverse outcome pathway development from protein alkylation to liver fibrosis. Arch Toxicol 2016; Epub ahead of print, doi:10.1007/ s00204-016-1814-8.

9. OECD. Users' handbook supplement to the guidance document for developing and assessing AOPs. $2014 \mathrm{http} / / /$ aopkb.org/common/AOP_Handbook.pdf (last accessed Sep. 23, 2016).

10. Meek ME, Palermo CM, Bachman AN, et al. Mode of action human relevance (species concordance) framework: Evolution of the Bradford Hill considerations and comparative analysis of weight of evidence. J Appl Toxicol 2014:34:595-606.

11. Förstermann U, Li H. Therapeutic effect of enhancing endothelial nitric oxide synthase (eNOS) expression and preventing eNOS uncoupling. Br J Pharmacol 2011:164; 213-223.

12. Whitsett J, Picklo MJ, Vasquez-Vivar J. 4-Hydroxy-2nonenal increases superoxide anion radical in endothelial cells via stimulated GTP cyclohydrolase proteasomal degradation. Arterioscler Thromb Vasc Biol 2007;27:23402347.

13. Vaziri ND, Ding Y. Effect of lead on nitric oxide synthase expression in coronary endothelial cells: Role of superoxide. Hypertension 2001:37;223-226.

14. Morgan PE, Sheahan PJ, Davies MJ. Perturbation of human coronary artery endothelial cell redox state and NADPH generation by methylglyoxal. PLoS One 2014:21;9:e86564.

15. Slemmer JE, Shacka JJ, Sweeney MI, et al. Antioxidants and free radical scavengers for the treatment of stroke, traumatic brain injury and aging. Curr Med Chem 2008:15;404-414.

16. Mehlhase J, Grune T. Proteolytic response to oxidative stress in mammalian cells. Biol Chem 2002:383;559-567.

17. Zheng L, Dong H, Su G, et al. Radical scavenging activities of Tyr-, Trp-, Cys- and Met-Gly and their protective effects against AAPH-induced oxidative damage in human erythrocytes. Food Chem 2016:15;197(Pt A):807-813.

18. Ceron CS, Marchi KC, Muniz JJ, et al. Vascular oxidative stress: A key factor in the development of hypertension associated with ethanol consumption. Curr Hypertens Rev 2014:10;213-222.

19. Kim M, Han CH, Lee MY. NADPH oxidase and the cardiovascular toxicity associated with smoking. Toxicol Res 2014:30:149-157.

20. Tseng CY, Wang JS, Chao MW. Causation by diesel exhaust particles of endothelial dysfunctions in cytotoxicity, pro-inflammation, permeability, and apoptosis induced by ROS generation. Cardiovasc Toxicol 2016 [Epub ahead of print]; DOI: 10.1007/s12012-016-9364-0.

21. Higashi Y, Maruhashi T, Noma K, et al. Oxidative stress and endothelial dysfunction: Clinical evidence and therapeutic implications. Trends Cardiovasc Med 2014:24;165-169.

22. Du Y, Navab M, Shen M, et al. Ambient ultrafine particles reduce endothelial nitric oxide production via S-glutathionylation of eNOS. Biochem Biophys Res Commun 2013: 436;462-466.

23. Dhar A, Dhar I, Desai KM, et al. Methylglyoxal scavengers attenuate endothelial dysfunction induced by methyl- glyoxal and high concentrations of glucose. Br J Pharmacol 2010:161;1843-1856.

24. van Gorp RM, Broers JL, Reutelingsperger CP, et al. Peroxide-induced membrane blebbing in endothelial cells associated with glutathione oxidation but not apoptosis. Am J Physiol 1999:277;C20-C28.

25. Park WH. The effects of exogenous $\mathrm{H} 2 \mathrm{O} 2$ on cell death, reactive oxygen species and glutathione levels in calf pulmonary artery and human umbilical vein endothelial cells. Int J Mol Med 2013:31;471-476.

26. Montecinos V, Guzmán P, Barra V, et al. Vitamin C is an essential antioxidant that enhances survival of oxidatively stressed human vascular endothelial cells in the presence of a vast molar excess of glutathione. J Biol Chem 2007; 282:15506-15515.

27. De Pascali F, Hemann C, Samons K, et al. Hypoxia and reoxygenation induce endothelial nitric oxide synthase uncoupling in endothelial cells through tetrahydrobiopterin depletion and S-glutathionylation. Biochemistry 2014:53;3679-3688.

28. Chen CA, Lin CH, Druhan LJ, et al. Superoxide induces endothelial nitric-oxide synthase protein thiyl radical formation, a novel mechanism regulating eNOS function and coupling. J Biol Chem 2011:286;29098-29107.

29. Schuppe I, Moldéus P, Cotgreave IA. Protein-specific Sthiolation in human endothelial cells during oxidative stress. Biochem Pharmacol 1992:44;1757-1764.

30. Chen CA, Wang TY, Varadharaj S, et al. S-glutathionylation uncouples eNOS and regulates its cellular and vascular function. Nature 2010:468;1115-1118.

31. Tatham AL, Crabtree MJ, Warrick N, et al. GTP cyclohydrolase I expression, protein, and activity determine intracellular tetrahydrobiopterin levels, independent of GTP cyclohydrolase feedback regulatory protein expression. $\mathbf{J}$ Biol Chem 2009:284;13660-13668.

32. Wang S, Xu J, Song P, et al. Acute inhibition of guanosine triphosphate cyclohydrolase 1 uncouples endothelial nitric oxide synthase and elevates blood pressure. Hypertension 2008:52;484-490.

33. Crabtree MJ, Tatham AL, Al-Wakeel Y, et al. Quantitative regulation of intracellular endothelial nitric-oxide synthase (eNOS) coupling by both tetrahydrobiopterin-eNOS stoichiometry and biopterin redox status: Insights from cells with tet-regulated GTP cyclohydrolase I expression. J Biol Chem 2009:284;1136-1144.

34. Biondi R, Ambrosio G, De Pascali F, et al. HPLC analysis of tetrahydrobiopterin and its pteridine derivatives using sequential electrochemical and fluorimetric detection: Application to tetrahydrobiopterin autoxidation and chemical oxidation. Arch Biochem Biophys 2012:520:7-16.

35. Förstermann U, Münzel T. Endothelial nitric oxide synthase in vascular disease: From marvel to menace. Circulation 2006:113; 1708-1714.

36. Jayaram R, Goodfellow N, Zhang MH, et al. Molecular mechanisms of myocardial nitroso-redox imbalance during on-pump cardiac surgery. Lancet Lond Engl 2015:385 Suppl 1:S49.

37. Zhao H, Kalivendi S, Zhang H, et al. Superoxide reacts with hydroethidine but forms a fluorescent product that is distinctly different from ethidium: Potential implications in intracellular fluorescence detection of superoxide. Free Radic Biol Med 2003:34;1359-1368.

38. EPR Detection of the Superoxide Free Radical with the Nitrone Spin Traps DMPO and BMPO. www.bruker.com/ fileadmin/user_upload/8-PDF-Docs/MagneticResonance/ 
EPR_brochures/superoxide.pdf (last accessed Dec. 7, 2016).

39. Dimmeler S, Fleming I, Fisslthaler B, et al. Activation of nitric oxide synthase in endothelial cells by Akt-dependent phosphorylation. Nature 1999:399;601-605.

40. Fulton D, Gratton JP, McCabe TJ, et al. Regulation of endothelium-derived nitric oxide production by the protein kinase Akt. Nature 1999:399;597-601.

41. Dudzinski DM, Michel T. Life history of eNOS: Partners and pathways. Cardiovasc Res 2007:75;247-260.

42. Du J, Fan LM, Mai A, et al. Crucial roles of Nox2-derived oxidative stress in deteriorating the function of insulin receptors and endothelium in dietary obesity of middle-aged mice. Br J Pharmacol 2013:170;1064-1077.

43. Du XL, Edelstein D, Dimmeler S, et al. Hyperglycemia inhibits endothelial nitric oxide synthase activity by posttranslational modification at the Akt site. J Clin Invest 2001:108;1341-1348.

44. Song $\mathrm{P}, \mathrm{Wu} \mathrm{Y}, \mathrm{Xu}$ J, et al. Reactive nitrogen species induced by hyperglycemia suppresses Akt signaling and triggers apoptosis by upregulating phosphatase PTEN (phosphatase and tensin homologue deleted on chromosome 10) in an LKB1-dependent manner. Circulation 2007:116;1585-1595.

45. Michaud SE, Dussault S, Groleau J, et al. Cigarette smoke exposure impairs VEGF-induced endothelial cell migration: Role of $\mathrm{NO}$ and reactive oxygen species. J Mol Cell Cardiol 2006:41;275-284.

46. Zou MH, Shi C, Cohen RA. Oxidation of the zinc-thiolate complex and uncoupling of endothelial nitric oxide synthase by peroxynitrite. J Clin Invest 2002:109;817-826.

47. Giles TD, Sander GE, Nossaman BD, et al. Impaired vasodilation in the pathogenesis of hypertension: Focus on nitric oxide, endothelial-derived hyperpolarizing factors, and prostaglandins. J Clin Hypertens 2012:14;198-205.

48. Kojda G, Laursen JB, Ramasamy S, et al. Protein expression, vascular reactivity and soluble guanylate cyclase activity in mice lacking the endothelial cell nitric oxide synthase: Contributions of NOS isoforms to blood pressure and heart rate control. Cardiovasc Res 1999:42;206-213.

49. Gupta JK, Igamberdiev AU. Recommendations of using at least two different methods for measuring NO. Front Plant Sci 2013;4:58.

50. Raitakari O, Celermajer DS. Flow-mediated dilatation. $\mathrm{Br}$ J Clin Pharmacol. 2000:50:397-404.

51. Mayet J, Hughes A. Cardiac and vascular pathophysiology in hypertension. Heart Br Card Soc 2003:89;1104-1109.

52. Stefadouros MA, Dougherty MJ, Grossman W, et al. Determination of systemic vascular resistance by a noninvasive technic. Circulation. 1973:47;101-107.

53. Pompella A, Visvikis A, Paolicchi A, et al. The changing faces of glutathione, a cellular protagonist. Biochem Pharmacol 2003:66;1499-1503.

54. Noctor G, Foyer CH. ASCORBATE AND GLUTATHIONE: Keeping active oxygen under control. Annu Rev Plant Physiol Plant Mol Biol 1998:49;249-279.

55. Michell BJ, Harris MB, Chen ZP, et al. Identification of regulatory sites of phosphorylation of the bovine endothelial nitric-oxide synthase at serine 617 and serine 635 . J Biol Chem 2002:277:42344-42351.

56. Chen C, Druhan L, Varadharaj S, et al. Phosphorylation of endothelial nitric-oxide synthase regulates superoxide generation from the enzyme. J Biol Chem 2008:283;2703827047.
57. Zhang QJ, McMillin SL, Tanner JM, et al. Endothelial nitric oxide synthase phosphorylation in treadmill-running mice: Role of vascular signalling kinases. J Physiol 2009:587(Pt 15);3911-3920.

58. Durand MJ, Gutterman DD. Diversity in mechanisms of endothelium-dependent vasodilation in health and disease. Microcirculation 2013:20;239-247.

59. Scotland RS, Madhani M, Chauhan S, et al. Investigation of vascular responses in endothelial nitric oxide synthase/ cyclooxygenase-1 double-knockout mice: Key role for endothelium-derived hyperpolarizing factor in the regulation of blood pressure in vivo. Circulation 2005:111;796-803.

60. Maranon R, Reckelhoff JF. Sex and gender differences in control of blood pressure. Clin Sci (Lond) 2013:125;311318.

61. Peng H, Zhuang Y, Chen Y, et al. The characteristics and regulatory mechanisms of superoxide generation from eNOS reductase domain. PLoS One 2015:10; e0140365.

62. Wu F, Szczepaniak WS, Shiva S, et al. Nox2-dependent glutathionylation of endothelial NOS leads to uncoupled superoxide production and endothelial barrier dysfunction in acute lung injury. Am J Physiol Lung Cell Mol Physiol 2014:307;L987-L997.

63. Chen CA, De Pascali F, Basye A, et al. Redox modulation of endothelial nitric oxide synthase by glutaredoxin-1 through reversible oxidative post-translational modification. Biochemistry 2013:52;6712-6723.

64. Nozik-Grayck E, Woods C, Taylor JM, et al. Selective depletion of vascular EC-SOD augments chronic hypoxic pulmonary hypertension. Am J Physiol Lung Cell Mol Physiol 2014:307;L868-L876.

65. Adlam D, Herring N, Douglas G, et al. Regulation of $\beta$ adrenergic control of heart rate by GTP-cyclohydrolase 1 (GCH1) and tetrahydrobiopterin. Cardiovasc Res 2012: 93;694-701.

66. Mitchell BM, Dorrance AM, Webb RC. GTP cyclohydrolase 1 inhibition attenuates vasodilation and increases blood pressure in rats. Am J Physiol Heart Circ Physiol 2003:285; H2165-H2170.

67. Meininger CJ, Cai S, Parker JL, et al. GTP cyclohydrolase I gene transfer reverses tetrahydrobiopterin deficiency and increases nitric oxide synthesis in endothelial cells and isolated vessels from diabetic rats. FASEB J 2004:18:19001902.

68. Meininger CJ, Marinos RS, Hatakeyama K, et al. Impaired nitric oxide production in coronary endothelial cells of the spontaneously diabetic $\mathrm{BB}$ rat is due to tetrahydrobiopterin deficiency. Biochem J 2000:349(Pt 1);353-356.

69. Alp NJ, Mussa S, Khoo J, et al. Tetrahydrobiopterindependent preservation of nitric oxide-mediated endothelial function in diabetes by targeted transgenic GTPcyclohydrolase I overexpression. J Clin Invest 2003: $112 ; 725-735$.

70. Ge ZD, Ionova IA, Vladic N, et al. Cardiac-specific overexpression of GTP cyclohydrolase 1 restores ischaemic preconditioning during hyperglycaemia. Cardiovasc Res 2011:91;340-349.

71. Du YH, Guan YY, Alp NJ, et al. Endothelium-specific GTP cyclohydrolase I overexpression attenuates blood pressure progression in salt-sensitive low-renin hypertension. Circulation 2008:117;1045-1054.

72. Cervantes-Pérez LG, Ibarra-Lara M, Escalante B, et al. Endothelial nitric oxide synthase impairment is restored 
by clofibrate treatment in an animal model of hypertension. Eur J Pharmacol 2012:685;108-115.

73. Heitzer T, Brockhoff C, Mayer B, et al. Tetrahydrobiopterin improves endothelium-dependent vasodilation in chronic smokers: Evidence for a dysfunctional nitric oxide synthase. Circ Res 2000:86;E36-E341.

74. Moreau KL, Meditz A, Deane KD, et al. Tetrahydrobiopterin improves endothelial function and decreases arterial stiffness in estrogen-deficient postmenopausal women. Am J Physiol Heart Circ Physiol 2012:302;H1211H1218.

75. Pierce L, Jablonski K, Walker A, et al. Tetrahydrobiopterin supplementation enhances carotid artery compliance in healthy older men: A pilot study. Am J Hypertens 2012:25;1050-1054.

76. Zou MH, Hou XY, Shi CM, et al. Modulation by peroxynitrite of Akt- and AMP-activated kinase-dependent Ser1179 phosphorylation of endothelial nitric oxide synthase. J Biol Chem 2002:277;32552-32557.

77. Laursen JB, Somers M, Kurz S, et al. Endothelial regulation of vasomotion in apoE-deficient mice implications for interactions between peroxynitrite and tetrahydrobiopterin. Circulation 2001:103;1282-1288.

78. Li L, Rezvan A, Salerno JC, et al. GTP cyclohydrolase I phosphorylation and interaction with GTP cyclohydrolase feedback regulatory protein provide novel regulation of endothelial tetrahydrobiopterin and nitric oxide. Circ Res 2010:106;328-336.

79. Bauersachs J, Schafer A. Tetrahydrobiopterin and eNOS dimer/monomer ratio- a clue to eNOS uncoupling in diabetes? Cardiovasc Res 2005:65;768-769.

80. Cai S, Khoo J, Channon KM. Augmented BH4 by gene transfer restores nitric oxide synthase function in hyperglycemic human endothelial cells. Cardiovasc Res 2005:65; 823-831.

81. Karbach S, Wenzel P, Waisman A, et al. eNOS uncoupling in cardiovascular diseases - the role of oxidative stress and inflammation. Curr Pharm Des 2014:20;3579-3594.

82. Duan DD, Kwan CY. A molecular switch of "yin and yang": S-glutathionylation of eNOS turns off NO synthesis and turns on superoxide generation. Acta Pharmacol Sin 2011:32;415-416.

83. Luo S, Lei H, Qin H, et al. Molecular mechanisms of endothelial NO synthase uncoupling. Curr Pharm Des 2014:20;35483553.

84. Zweier JL, Chen CA, Druhan LJ. S-glutathionylation reshapes our understanding of endothelial nitric oxide synthase uncoupling and nitric oxide/reactive oxygen species-mediated signaling. Antioxid Redox Signal 2011:14;1769-1775.

85. Dumitrescu C, Biondi R, Xia Y, et al. Myocardial ischemia results in tetrahydrobiopterin (BH4) oxidation with impaired endothelial function ameliorated by $\mathrm{BH} 4$. Proc Natl Acad Sci U S A 2007:104;15081-15086.

86. Tiefenbacher CP, Chilian WM, Mitchell M, et al. Restoration of endothelium-dependent vasodilation after reperfusion injury by tetrahydrobiopterin. Circulation 1996:94;14231429.

87. Vásquez-Vivar J, Martásek $\mathrm{P}$, Whitsett $\mathrm{J}$, et al. The ratio between tetrahydrobiopterin and oxidized tetrahydrobiopterin analogues controls superoxide release from endothelial nitric oxide synthase: An EPR spin trapping study. Biochem J 2002:362(Pt 3);733-739.

88. Crabtree MJ, Brixey R, Batchelor $\mathrm{H}$, et al. Integrated redox sensor and effector functions for tetrahydrobiopterin- and glutathionylation-dependent endothelial nitric-oxide synthase uncoupling. J Biol Chem 2013:288;561-569.

89. Das A, Gopalakrishnan B, Druhan LJ, et al. Reversal of SIN-1-induced eNOS dysfunction by the spin trap, DMPO, in bovine aortic endothelial cells via eNOS phosphorylation. Br J Pharmacol 2014:171;2321-2334.

90. Su Y, Qadri SM, Wu L, et al. Methylglyoxal modulates endothelial nitric oxide synthase-associated functions in EA.hy926 endothelial cells. Cardiovasc Diabetol 2013:12;134.

91. Zhang WZ, Venardos K, Chin-Dusting J, et al. Adverse effects of cigarette smoke on NO bioavailability: Role of arginine metabolism and oxidative stress. Hypertension 2006:48;278-285.

92. Choi YJ, Yoon Y, Lee KY, et al. Uric acid induces endothelial dysfunction by vascular insulin resistance associated with the impairment of nitric oxide synthesis. FASEB J 2014:28;3197-3204.

93. Choi YJ, Yoon Y, Lee KY, et al. Orotic acid induces hypertension associated with impaired endothelial nitric oxide synthesis. Toxicol Sci 2015:144;307-317.

94. Uruno A, Sugawara A, Kanatsuka H, et al. Upregulation of nitric oxide production in vascular endothelial cells by alltrans retinoic acid through the phosphoinositide 3-kinase/ Akt pathway. Circulation 2005:112;727-736.

95. Huang PL. Mouse models of nitric oxide synthase deficiency. J Am Soc Nephrol 2000:11 Suppl 16;S120-S123.

96. Huang PL, Huang Z, Mashimo $\mathrm{H}$, et al. Hypertension in mice lacking the gene for endothelial nitric oxide synthase. Nature 1995:377:239-242.

97. Sander M, Chavoshan B, Victor RG. A large blood pressure-raising effect of nitric oxide synthase inhibition in humans. Hypertension 1999:33;937-942.

98. Taylor BA, Zaleski AL, Dornelas EA, et al. The impact of tetrahydrobiopterin administration on endothelial function before and after smoking cessation in chronic smokers. Hypertens Res 2016:39;144-150.

99. Carnevale R, Sciarretta S, Violi F, et al. Acute impact of tobacco vs. electronic cigarette smoking on oxidative stress and vascular function. Chest 2016:150;606-612.

100. Li J, Zhou Z, Jiang DJ, et al. Reduction of NO- and EDHFmediated vasodilatation in hypertension: Role of asymmetric dimethylarginine. Clin Exp Hypertens 2007:29;489-501.

101. McVeigh GE, Allen PB, Morgan DR, et al. Nitric oxide modulation of blood vessel tone identified by arterial waveform analysis. Clin Sci (Lond) 2001:100;387-393.

102. Paulis L, Zicha J, Kunes J, et al. Regression of L-NAMEinduced hypertension: The role of nitric oxide and endothelium-derived constricting factor. Hypertens Res 2008:31;793-803.

103. Wilkinson IB, MacCallum H, Cockcroft JR, et al. Inhibition of basal nitric oxide synthesis increases aortic augmentation index and pulse wave velocity in vivo. Br J Clin Pharmacol 2002:53;189-192.

104. Talukder MA, Johnson WM, Varadharaj S, et al. Chronic cigarette smoking causes hypertension, increased oxidative stress, impaired NO bioavailability, endothelial dysfunction, and cardiac remodeling in mice. (2011) Am J Physiol Heart Circ Physiol 300:H388-H896.

105. Luo Z, Fujio Y, Kureishi Y, et al. Acute modulation of endothelial Akt/PKB activity alters nitric oxide-dependent vasomotor activity in vivo. J Clin Invest 2000:106;493-499.

106. Sélley E, Kun S, Szijártó IA, et al. Exenatide induces aortic vasodilation increasing hydrogen sulphide, carbon monoxide 
and nitric oxide production. Cardiovasc Diabetol 2014: $13 ; 69$.

107. Brett SE, Cockcroft JR, Mant TG, et al. Haemodynamic effects of inhibition of nitric oxide synthase and of L-arginine at rest and during exercise. J Hypertens 1998:16;429-435.

108. Stamler JS, Loh E, Roddy MA, et al. Nitric oxide regulates basal systemic and pulmonary vascular resistance in healthy humans. Circulation 1994:89;2035-2040.

109. Haynes WG, Noon JP, Walker BR, et al. Inhibition of nitric oxide synthesis increases blood pressure in healthy humans. J Hypertens 1993:11;1375-1380.

110. Immink RV, van den Born BJ, van Montfrans GA, et al. Cerebral hemodynamics during treatment with sodium nitroprusside versus labetalol in malignant hypertension. Hypertension 2008:52;236-240.

111. Elkayam U, Ng TM, Hatamizadeh P, et al. Renal vasodilatory action of dopamine in patients with heart failure: Magnitude of effect and site of action. Circulation 2008:117; 200-205.

112. Gerson JI, Allen FB, Seltzer JL, et al. Arterial and venous dilation by nitroprusside and nitroglycerin-is there a difference? Anesth Analg 1982:61;256-260.

113. Stratton JR, Pfeifer MA, Ritchie JL, et al. Hemodynamic effects of epinephrine: Concentration-effect study in humans. 1985:58;1199-1206.

114. Santos-Parker JR, LaRocca TJ, Seals DR. Aerobic exercise and other healthy lifestyle factors that influence vascular aging. Adv Physiol Educ 2014:38;296-307.

115. Brandes RP. Endothelial dysfunction and hypertension. Hypertension 2014:64;924-928.

116. Foëx P, Sear JW. Hypertension: Pathophysiology and treatment. Contin Educ Anaesth Crit Care Pain 2004:4;71-75.

117. Chan SS, Tse MM, Chan CP, et al. Haemodynamic changes in emergency department patients with poorly controlled hypertension. Hong Kong Med J 2016:22;116-123.

118. Bendall JK, Douglas G, McNeill E, et al. Tetrahydrobiopterin in cardiovascular health and disease. Antioxid Redox Signal 2014:20;3040-3077.

119. Siddiqui A. Effects of vasodilation and arterial resistance on cardiac output. J Clin Exp Cardiol 2011:2;170.

120. van Gorp RM, Heeneman S, Broers JL et al. Glutathione oxidation in calcium- and p38 MAPK-dependent membrane blebbing of endothelial cells. Biochim Biophys Acta 2002:1591;129-138.

121. Guttmann RP. Redox regulation of cysteine-dependent enzymes. J Anim Sci 2010:88;1297-1306.

122. Antoniades C, Cunnington C, Antonopoulos A, et al. Induction of vascular GTP-cyclohydrolase I and endogenous tet- rahydrobiopterin synthesis protect against inflammationinduced endothelial dysfunction in human atherosclerosis. Circulation 2011:124;1860-1870.

123. Chuaiphichai S, McNeill E, Douglas G, et al. Cellautonomous role of endothelial GTP cyclohydrolase 1 and tetrahydrobiopterin in blood pressure regulation. Hypertension 2014:64;530-540.

124. Landmesser U, Dikalov S, Price SR, et al. Oxidation of tetrahydrobiopterin leads to uncoupling of endothelial cell nitric oxide synthase in hypertension. J Clin Invest 2003: 111;1201-1209.

125. Ozaki M, Kawashima S, Yamashita T, et al. Overexpression of endothelial nitric oxide synthase accelerates atherosclerotic lesion formation in apoE-deficient mice. J Clin Invest 2002:110;331-340.

126. Shinozaki K, Nishio Y, Okamura T, et al. Oral administration of tetrahydrobiopterin prevents endothelial dysfunction and vascular oxidative stress in the aortas of insulinresistant rats. Circ Res 2000:87;566-573.

127. Zhang W, Han Y, Meng G, et al. Direct renin inhibition with aliskiren protects against myocardial ischemia/reperfusion injury by activating nitric oxide synthase signaling in spontaneously hypertensive rats. J Am Heart Assoc 2014:3;e000606.

128. Su Y, Liu XM, Sun YM, et al. The relationship between endothelial dysfunction and oxidative stress in diabetes and prediabetes. Int J Clin Pract 2008:62;877-882.

129. Song $\mathrm{P}, \mathrm{Xie} \mathrm{Z}, \mathrm{Wu} \mathrm{Y}$, et al. Protein kinase Czetadependent LKB1 serine 428 phosphorylation increases LKB1 nucleus export and apoptosis in endothelial cells. J Biol Chem 2008:283;12446-12455.

130. Galougahi KK, Liu CC, Gentile C, et al. Glutathionylation mediates angiotensin II-induced eNOS uncoupling, amplifying NADPH oxidase-dependent endothelial dysfunction. J Am Heart Assoc 2014:3; 0000731 .

131. Kopilas MA, Dang LN, Anderson HD. Effect of dietary chromium on resistance artery function and nitric oxide signaling in the sucrose-fed spontaneously hypertensive rat. J Vasc Res 2007:44;110-118.

Address correspondence to:

Frazer J. Lowe

British American Tobacco (Investments) Ltd. Group Research and Development Southampton SO15 8TL United Kingdom

E-mail: frazer_lowe@bat.com 